\section{Comparison of the Effects of Plant Parables on the Promotion of Spiritual Benefits in Students with Differing Horticultural Backgrounds}

\author{
Wan-Wei Yu ${ }^{1}$, Der-Lin Ling ${ }^{1}$, and Yu-Sen Chang ${ }^{1,2}$
}

ADDITIONAL INDEX WORDs. therapeutic horticulture, restoration, aesthetics

SUMMARY. Research on the restorative benefits of nature primarily has focused on the spiritual benefits of wilderness areas, but other areas, such as cities, have not been studied. Horticultural activities have the potential to promote spiritual health, but most participants are not aware of this benefit. To improve this situation and to increase evidence of the benefits of therapeutic horticulture, this study suggests treating plant parables as trigger cues, which would allow an approach to interaction with plants through metaphysical imagination, resulting in an improvement in spiritual health from horticultural activities. The purpose of this study was to understand participants' beliefs of the spiritual benefits of horticultural activities, and to see if these beliefs were enhanced after reading plant parables. This study surveyed subjects with different horticultural backgrounds, and measured their opinions regarding belief in the spiritual benefits of horticultural activities, before and after reading the parables. The results indicated that before reading the plant parables, neither group of subjects with different horticultural backgrounds agreed with the spiritual benefits of horticultural activities; however, after reading the plant parables, the belief of participants with formal horticultural education backgrounds increased significantly $(P \leq 0.001)$. The increase was not significant in subjects without formal horticultural education backgrounds.

S piritual health is a new field of health promotion that has gradually become more important in recent years (Vader, 2006). Classical definitions of spirituality tend to concentrate on religious and ecclesiastical matters or matters concerned with the soul, but current studies adopt much wider definitions (Fisher et al., 2000). Spirituality is defined as having a meaning and a direction in life. Spirituality involves the development of positive morals, ethics, and values. Being healthy spiritually helps us to demonstrate love, hope, and a sense of caring for oneself and others (School District 6, 2009). Spiritual health is related to other aspects of health (physical, mental, and social) and is seen as a basic resource of other health aspects. Spiritual health leads to vitality and improved behavior and motivation (Hsiao and Huang, 2005). It also allows individuals to live more meaningful lives. Spiritual well-being is regarded as an essential need of human beings; however, there have been practical difficulties in identifying, defining, and measuring this dimension (Vader, 2006).

\footnotetext{
${ }^{1}$ Department of Horticulture, National Taiwan University, Taipei, 106, Taiwan

${ }^{2}$ Corresponding author. E-mail: yschang@ntu.edu.tw
}

Due to this difficulty in outlining spirituality, spiritual health studies in different fields are in their early stages.

Research on the restorative effects of nature (Bell et al., 2001) has focused on physical and psychological benefits instead of spiritual benefits. The physical and psychological benefits derived from natural environments can be applied to urban areas, but these are often transient (Hietanen and Korpela, 2004). Previous research has shown that to obtain long-term spiritual benefits, people must spend a greater amount of time in natural environments that have the potential to lead to deep restorative experiences that can provide the opportunity to reflect on life's larger questions such as one's priorities, goals, and one's place in the overall scheme of things, and the sense of "being at one with the universe" (Herzog et al., 1997; Kaplan and Kaplan, 1989). However, these studies have focused only on wilderness areas (Fredrickson and Anderson, 1999; Heintzman, 2002; Kaplan and Talbot, 1983; Williams and Harvey, 2001) or were conducted in locations with significant spiritual meaning, such as monasteries (Ouellette et al., 2005). There are few studies on how nature in urban areas leads to spiritual benefits.
Explanations of the restorative effects of nature are related to visual preferences (Kaplan et al., 1998; Ulrich, 1983) and follow the classical idea of disinterested contemplation of sensuous and formal properties (e.g., lines, form, color, or textures) of isolated and solitary pieces of art (Carlson and Berleant, 2004). Most of the research based on disinterested contemplation indicates that these restorative effects are temporary because the appreciation is usually trivial and superficial. On the other hand, "there is in the appreciation of nature, a movement from shallow and trivial to deep, serious aesthetic experience" (Carlson and Berleant, 2004). Serious aesthetic experience is an engaged experience that comes from the participant's point of view and occurs within an environment (Berleant, 1997; Carlson, 2002). It is an open, engaging, and creative mode of appreciation, guided by realizations on the character of the natural world (Carlson and Berleant, 2004; Hepburn, 1966).

The many-leveled structure of an aesthetic experience of nature can include a great diversity of constituents, from the most particular-rocks, stones, leaves, clouds, shadows-to the most abstract and general ways that we comprehend the world as a whole. The landscape can be viewed as ominous, cosmically ominous, or as revealing and concealing great beauty (Hepburn, 2004). During highleveled aesthetic experiences, people often have philosophical feelings and an understanding of life, history, and the universe ( $\mathrm{Li}, 2001$; Ye, 1993). There are many similarities between an aesthetic and restorative experience (Yu et al., 2006). Thus, spiritual benefit can be considered a result of a highly aesthetic experience. To promote the spiritual benefits of nature, the aesthetic experience must be enhanced.

Metaphysical imagination is the contemplation of perceptible analogies between life and the scene before us and provides a superior aesthetic experience because it transforms scientific knowledge of scenes to metaphysical principles of life (Hepburn, 2004). It is a component of the experience of the present landscape; it is fused with sensory components, but is not a meditation aroused by the surroundings (Hepburn, 2004). Metaphysical imagination can avoid 
shallow or trivial appreciation that results from personal and emotional responses (Carlson, 2009). Thus, it produces convincing results that are persistent and are different from temporary fantasy (Hepburn, 2004). With metaphysical imagination, people can interpret nature as an inspirational, generalized, and metaphysical truth and can achieve a vision of the meaning of life, the human condition, and the human position in the universe. This concept is similar to the beliefs of the ancient Chinese; the principles of humans and the universe are based upon the same system, and by observing the ways of nature, people can recognize these principles of their own lives (Chuang Tzu, n.d.). Thus, a highly aesthetic experience could result in spiritual benefits.

Horticultural activities are interactive compared with static scenery appreciation; thus, they have more potential to result in highly aesthetic experiences (Yu et al., 2006). However, if the participants treat horticultural knowledge simply as scientific knowledge, they cannot achieve highly aesthetic experiences. The participants must be capable of metaphysical imagination to transform the scientific knowledge of horticultural activities into the metaphysical principles of life and acquire spiritual benefits (Yu et al., 2006). To determine practical approaches for triggering metaphysical imagination, this study reviews the content of classical Chinese literature and the Christian Bible and treats plant parables as trigger cues for metaphysical imagination.

The ancient Chinese often compared the characteristics of plants to personality traits (Cheng, 1992; Jin, 2005). For instance, in the Lotus Flower, the lotus springs out of muddy water without a trace of dirt, implying that when a person encounters a difficult environment, he/she will not be affected and his/her dignity remains pure. In the New Testament of the Bible, Jesus compares the results of spreading seeds onto different types of land to people's attitudes in accepting the Gospel from the Kingdom of Heaven, (Chapter 13, Matthew). People can better understand their lives by comparing them to famous plant parables.

Therefore, horticultural activities may have the potential to promote spiritual health. Because therapeutic horticulture currently refers only to physical, psychological, and social benefits (Relf, 1998), the purpose of this study was to understand participants' beliefs about the spiritual benefits of horticultural activities and to discover if these beliefs were enhanced after reading plant parables.

\section{Material and methods Subjects}

The subjects in this study were university students from the National Taiwan University. They were divided into two groups according to their horticultural background. Group 1 consisted of students from diverse departments other than the Department of Horticulture. The students were surveyed in a general education course (the title of the course was "From Money to Chinese History") on 12 May 2009. Subjects were asked if they grew plants in their daily lives. They were given the choice of "no," "sometimes," "usually," or "continually." Those participants who answered "no" (67 participants) were not analyzed. The remaining subjects were considered as having experience with plants in their daily lives. They were asked to complete all sections of the questionnaire, and their survey results were analyzed. Among the 103 questionnaires distributed, seven were eliminated because of incomplete answers and only 29 students had experience with plants in their daily lives. Most of the 29 qualified subjects were natural science majors $(72 \%)$. These individuals were considered subjects who possessed personal plants and had nonformal horticultural education backgrounds.

Students in Group 2 were from the Department of Horticulture. They were surveyed as part of a required course in the Department of Horticulture. Among the 40 questionnaires distributed, one was eliminated because of incomplete answers. Ten were not analyzed because those students who respond to the survey did not grow plants in their daily lives. In total, 29 students were determined to have experience with plants in their daily lives. Compared with Group 1, these students had taken advanced courses in horticulture and gained training in cultivation. Therefore, the subjects of Group 2 were considered to have formal backgrounds in horticulture.

\section{Questionnaire}

This study collected data from self-reported questionnaires. The questionnaires included four sections: demographic questions, a pre-test of opinions on the spiritual benefits of horticultural activities, plant parables, and a post-test of opinions on the spiritual benefits of horticultural activities.

DE M OGRA P H I C S URVEY QUESTIONS. Demographic questions referred to gender, major, horticultural interests, and horticultural experience in the students' daily lives.

SPIRITUAL HEALTH SURVEY QUeSTIONS. Pre-test and post-test questions on the perceived spiritual benefits of horticultural activities represented the participants' thoughts about spiritual benefits from horticultural activities. In the pre-test, the instructions asked subjects to recall their experiences growing plants. Respondents described the experiences by indicating their level of agreement using a Likert-scale rating system (15 points, with $\mathrm{l}=$ "strongly disagree" and $5=$ "strongly agree"). After reading plant parables, the instructions of the post-test asked subjects to reconsider if they had gained these benefits from growing plants.

Each statement was chosen from the spiritual health scale constructed by Hsiao and Huang (2005). The scale was used because it is related to Taiwanese culture and would, therefore, appropriately correlate with the basic cultural values of the test groups of students. Most of the foreign spiritual health scales are based on Christianity and are, therefore, not suitable for the diverse and sometimes polytheistic religions in Taiwan (Hsiao et al., 2007). The spiritual health scale includes five dimensions: meaning derived from living, self-understanding, transcendence, connection to others, and religious attachment. It offers satisfactory validity and can be applied to assess the spiritual health status of individuals (Hsiao and Huang, 2005).

Because the scale aims to assess the subjects' spiritual health in general, it is different from this study, which intended to survey the thoughts that an individual has about the spiritual benefits derived from horticultural activities. Thus, the syntax of the statements for this study was modified. For instance, the item 
Table 1. The dimensions of the spiritual health scale (Hsiao and Huang, 2005) and items related to each dimension, modified to include the pre- and post-test of the perceived spiritual benefits of horticultural activities. Respondents described the experiences by indicating their level of agreement using a five-point Likertscale rating system, with $\mathbf{l}=$ "strongly disagree" and $\mathbf{5}=$ "strongly agree."

\section{Dimensions of spiritual health scale}

Meaning derived from living

Self-understanding

Transcendence

Connection to others

Religious attachment
Items with the beginning statement of "I think horticultural activities can help me"

To deliberate on issues related to the meaning of life

To ponder how to enrich my life

To ponder my current goals

To ponder my future objectives in life

To try to have a meaningful life

To understand myself

To appreciate my advantages

To accept my disadvantages

To like myself

To think I am a valuable person

To consider the frustration of life as meaningful

Not to be afraid when I encounter frustrations

To accept the unexpected incidences in life

To convince myself that I can change my attitude when I encounter frustrations

To face the frustration of live with a positive and optimistic attitude

To convince that everyone exists for a significant purpose

To get along with most of my friends

To convince myself that there is an invisible power

To convince myself that religion allows me to overcome difficulties from the original scale that read "I will deliberate on the issues related to the meaning of life" was modified to read "horticultural activities help me in deliberating the issues related to the meaning of life." Some items in the original scale did not match the introductory statement of "horticultural activities benefit me"; thus, from the 47 items in the original scale, this study selected 19 items for modification. The items are shown in Table 1. The split-half reliabilities were corrected by the Spearman-Brown formula for the pre- and post-test, and the values were 0.888 and 0.941 , respectively.

Plant parables. Regarding the section of the plant parables, this study selected four parables that were taken from internet articles and maxims related to raising plants or plant growth (Table 2). They were selected because they all had some metaphors that connected to human life. For this study, the researcher invited subjects to read these parables carefully in private. The subjects were then given two tasks to ensure that they were reading carefully. One task asked about their favorite parable, and the other asked them to rate each parable on a scale of 1 to 5 , with

Table 2. The source and the content of plant parables that represent the transformation of scientific knowledge into metaphysical principles of life. They served as trigger cues to promote metaphysical imagination, which the subjects were asked to read after finishing the pre-test of the perceived spiritual benefits of horticultural activities.

Parable 1

Adapted from Hou (2007)

When we frequently water the saplings in the garden, the saplings become accustomed to the comfortable environment on the surface of the soil. They always wait for the water from the ground. However, with less watering, the saplings grow slowly and thus the roots can grow deep into the soil for water and nutrients. They will have deeper roots and be able to endure the severe climate.

A father realizes that he should not pray for his children to live easy lives and not try to avoid their frustration and tribulations. He should expect his children to grow with deep roots. This way they will obtain the best nutrients from the most difficult places.

Parable 2

Jung (1990)

Even the evergreen pines will wither when they are first transplanted to fertile soil. Likewise, when the environment changes, people will encounter immediate difficulties.

Parable 3

Adapted from $\mathrm{Zi}(2005)$

A florist told me "almost all kinds of white flowers, as opposed to colorful ones, are fragrant." He concluded that "likewise, simple people will usually have an inner fragrance."

Parable 4

B.-Y. Sung (unpublished)

When growing Bonsai, maintaining vitality is the key and depends on watering. "Watering requires ten years of practice". This means that watering should be adjusted according to the characteristics of different kinds of trees, climates, environmental changes, and the soil. It requires careful observation. If people attentively water the trees with sincere care, the leaves will be bright.

The results of the people's deeds will depend on their sincerity and care. Even trees, not to mention people, feel the care from men. This demonstrates the importance of interpersonal relationships. 
1 being "superficial" and 5 being "profound."

\section{Procedure}

It took approximately $10 \mathrm{~min}$ for the subjects to complete the questionnaire. After the pre-test, the subjects read the plant parables individually, and then they completed the post-test. The results were based on the scores of the pre- and post-test to determine if the subjects' agreement with the spiritual benefits of horticultural activities differed before and after reading the plant parables.

\section{Results}

There was no significant difference in the pre-test results from the two groups, as determined by the independent-sample $t$ test $(\mathrm{t}=-0.63$, $P=0.531)$. The total pre-test score of Group 1 was 50.76 and that of Group 2 was 53.34 , with both being less than 57 (the medium level of agreement of 3 points for each of the 19 items). This indicates that whether the subjects had a horticultural background or not, the subjects did not agree that horticultural activities can enhance personal spiritual benefits before reading the plant parables. After reading the plant parables, only the total scores of
Group 2 were greater than 57 in the post-test.

A paired-sample $t$ test was conducted to analyze the total scores of the pre- and post-test in Groups 1 and 2 . The results are shown in Table 3. The difference in comparisons of the total scores in the pre- and post-test in Group 1 is not significant. The total scores of the post-test are significantly higher than those of the pre-test in Group $2(\mathrm{t}=-4.830, P \leq 0.001)$. In regard to the spiritual benefits of horticultural activities, reading plant parables can significantly enhance the agreement of subjects that have formal backgrounds in horticulture, as can the promotion of horticultural activities on spiritual benefits. However, the plant parables did not significantly enhance a person's agreement with the spiritual benefits of horticultural activities if they possessed a nonformal educational background in horticulture.

This study then analyzed the difference of the means in the preand post-tests in the five dimensions mentioned above (Table 4 ). The results demonstrate that the pre- and post-test means of Group 1 did not have significant differences; among the five dimensions of Group 2, only

Table 3. Summary of the $t$ tests applied to examine the differences in the spiritual benefits from horticultural activities between the pre-test and post-test questionnaire results, based on 58 valid questionnaires of university students with non-formal (Group 1) or formal (Group 2) backgrounds in horticulture.

Total scores

\begin{tabular}{|c|c|c|c|c|c|c|}
\hline \multirow{2}{*}{$\begin{array}{l}\text { of spiritual health } \\
\text { benefits }\end{array}$} & \multicolumn{3}{|c|}{ Group $1(n=29)$} & \multicolumn{3}{|c|}{ Group $2(n=29)$} \\
\hline & Mean & SD & $\mathrm{t}$ & Mean & SD & $\mathbf{t}$ \\
\hline Pre-test & 50.76 & 16.22 & $-1.967 \mathrm{NS}$ & 53.34 & 15.03 & $-4.830 * * *$ \\
\hline Post-test & 53.34 & 17.00 & & 59.52 & 16.60 & \\
\hline
\end{tabular}

NS, ${ }^{* * *}$ Not significant or significant at $P \leq 0.001$.

Table 4. Summary of the $t$ tests applied to examine the differences in the five spiritual health dimensions from horticultural activities between the pre-test and post-test questionnaire responses, based on 58 valid questionnaires of university students with non-formal (Group 1) or formal (Group 2) backgrounds in horticulture.

\begin{tabular}{|c|c|c|c|c|c|c|c|c|c|}
\hline \multirow{2}{*}{\multicolumn{2}{|c|}{ Mean score of spiritual health dimension }} & \multicolumn{4}{|c|}{ Group $1(n=29)$} & \multicolumn{4}{|c|}{ Group $2(n=29)$} \\
\hline & & \multirow{2}{*}{$\frac{\text { Mean }}{2.81}$} & \multirow{2}{*}{$\frac{\mathrm{SD}}{0.91}$} & \multirow{2}{*}{$\frac{\mathbf{t}}{-1.509}$} & \multirow{2}{*}{$\frac{P}{0.143}$} & \multirow{2}{*}{$\begin{array}{c}\text { Mean } \\
2.80\end{array}$} & \multirow{2}{*}{$\begin{array}{c}\mathrm{SD} \\
0.94\end{array}$} & \multirow{2}{*}{$\frac{\mathbf{t}}{-3.993}$} & \multirow{2}{*}{$\frac{P}{0.000 * * *}$} \\
\hline Meaning derived from living & Pre-test & & & & & & & & \\
\hline \multirow{2}{*}{ Self-understanding } & Pre-test & 2.68 & 0.95 & -0.790 & 0.436 & 2.71 & 0.80 & -3.694 & $0.001 * * *$ \\
\hline & Post-test & 2.77 & 1.01 & & & 3.03 & 0.96 & & \\
\hline Transcendence & Pre-test & 2.58 & 0.88 & -1.745 & 0.092 & 2.87 & 0.86 & -3.313 & $0.002 * *$ \\
\hline & Post-test & 2.74 & 1.01 & & & 3.30 & 0.88 & & \\
\hline \multirow[t]{2}{*}{ Religious attachment } & Pre-test & 2.57 & 1.05 & 0.338 & 0.738 & 2.78 & 0.98 & -1.765 & 0.088 \\
\hline & Post-test & 2.53 & 1.01 & & & 2.92 & 0.97 & & \\
\hline
\end{tabular}

NS, ${ }^{*}, * *, * *$ Not significant or significant at $P \leq 0.05,0.01$, or 0.001 , respectively. 
the understanding of the meaning that comes from aesthetic experiences (Carlson, 2002), which may be due to the amount of horticultural knowledge and the level of training in cultivation. Students with formal backgrounds in horticulture have more related knowledge and cultivation training; thus, they can accumulate more knowledge and have more opportunities to effectively transform this knowledge into metaphysical truth compared with those whom have little or no related education background. According to the findings of this study, for those with rich horticultural knowledge and cultivation training, written presentation is sufficient to instruct the individual on how to promote spiritual benefits through horticultural activities. For those without much horticultural knowledge and cultivation training, the written presentation is not sufficient. It is possible that these subjects need more knowledge about horticultural operations to better understand the plant parables to promote spiritual benefits by horticultural activities. Future studies can examine the enhancing effect of plant parables by using a series of horticultural courses for those with no horticultural background. Also, the students who stated that they had no experience with plants could be studied to compare those with some experience and those with formal educational background.

Among the five dimensions of spiritual health, "meaning derived from living," "self-understanding," and "transcendence" are the most statistically significant factors. "Meaning derived from living" means that one can understand the purpose, meaning, and value of oneself. "Selfunderstanding" means that one has self-acceptance and self-appreciation. "Transcendence" is the belief that one can face the situation, accept the situation, change one's mind, and search for help when confronting frustrations. From the results of this research, it seems that these dimensions have much connection with growing plants. These dimensions also correspond to the deep restorative effects of wilderness areas (Fredrickson and Anderson, 1999; Kaplan and Talbot, 1983; Williams and Harvey, 2001). Religious attachment was not enhanced by the plant parables presented in this research. The effect of religious attachment is not easily seen with horticultural activities, which could be due to the limitations of the types of parables, an insignificant understanding of religion in Taiwanese culture, or that readers felt that religion could be seen as having little connection with growing plants. Future studies can focus on the dimensions that have more connection with growing plants or probe the possible effects of different types of parables.

\section{Literature cited}

Bell, P.A., T.C. Greene, J.D. Fisher, and A. Baum. 2001. Environmental psychology. 5th ed. Thomson, Belmont, CA.

Berleant, A. 1997. Living in the landscape: Toward an aesthetics of environment. University Press of Kansas, Lawrence, KS.

Carlson, A. 2002. Aesthetics and the environment: The appreciation of nature, art and architecture. Routledge, New York.

Carlson, A. 2009. Nature and landscape: An introduction to environmental aesthetics. Columbia University Press, New York.

Carlson, A. and A. Berleant. 2004. Introduction: The aesthetics of nature, p. 11-42. In: A. Carlson and A. Berleant (eds.). The aesthetics of natural environments. Broadview Press, Toronto, ON, Canada.

Cheng, F.-W. 1992. Shenyu wuyou: The approach of traditional Chinese aesthetics. Shangding Press, Taipei, Taiwan. (In Chinese).

Chuang Tzu. n.d. Based on James Legge's translation. 22: Knowledge rambling in the north. 27 Oct. 2009. <http:// oaks.nvg.org/zhuangzi22-.html>.

Fisher, J.W., L.J. Francis, and P. Johnson. 2000. Assessing spiritual health via four domains of spiritual wellbeing: The SH4DI. Pastoral Psychol. 49:133-145.

Fredrickson, L.M. and D.H. Anderson. 1999. A qualitative exploration of the wilderness experience as a source of spiritual inspiration. J. Environ. Psychol. 19:21-39.

Heintzman, P. 2002. A conceptual model of leisure and spiritual well-being. J. Park Recreation Administration 20:147-169.

Hepburn, R.W. 1966. Contemporary aesthetics and the neglect of natural beauty, p. 285-310. In: B. Williams and
A. Montefiore (eds.). British analytical philosophy. Routledge and Kegan Paul, London.

Hepburn, R.W. 2004. Landscape and the metaphysical imagination, p. 127-140. In: A. Carlson, and A. Berleant (eds.). The aesthetics of natural environments. Broadview Press, Toronto, ON, Canada.

Herzog, T.R., A.M. Black, K.A. Fountaine, and D.J. Knotts. 1997. Reflection and attentional recovery as distinctive benefits of restorative environments. J. Environ. Psychol. 17(2):165-170.

Hietanen, J.K. and K.M. Korpela. 2004. Do both negative and positive environmental scenes elicit rapid affective processing? Environ. Behav. 36:558-577.

Hou, Q. 2007. Trees will be flourishing after deep growing roots. 28 Oct. 2009. <http://blog.xuite.net/arvin66/icsc/ 11912884>. (In Chinese).

Hsiao, Y.-C. and S.-Y. Huang. 2005. Constructing and evaluating the reliability and validity of a scale to assess spiritual health: A nursing student sample. J. Evidence-Based Nursing 1:218-227. (In Chinese).

Hsiao, Y.-C., S.-Y. Huang, and M.-Y. Chen. 2007. A study of the relationships between religion, spiritual health and health promoting behavior. J. EvidenceBased Nursing 3:271-279. (In Chinese).

Jin, X.-Z. 2005. China park thesis. China Architecture and Building Press, Peking, China. (In Chinese).

Jung, J. 1990. Heaven's words, my words, Vol. 1. Chinese Christian Youth Assn., Taipei, Taiwan. (In Chinese).

Kaplan, R. and S. Kaplan. 1989. The experience of nature: A psychological perspective. Cambridge University Press, New York.

Kaplan, R., S. Kaplan, and R.L. Ryan. 1998. With people in mind. Island Press, Washington, DC.

Kaplan, S. and J.F. Talbot. 1983. Psychological benefits of a wilderness experience, p. 163-203. In: I. Altman and J.F. Wohlwill (eds.). Human behavior and environment: Advances in theory and research, Vol. 6. Plenum, New York.

Li, T.-H. 2001. Four lectures about aesthetics. Sanmin Press, Taipei, Taiwan. (In Chinese).

Ouellette, R., R. Kaplan, and S. Kaplan. 2005. The monastery as a restorative environment. J. Environ. Psychol. 25:175188.

Relf, P.D. 1998. People-plant relationship, p. 21-42. In: SimsonS., and M.C. 
Straus (eds.). Horticulture as therapy: Principles and practice. Haworth Press, New York.

School District 6. 2009. Spiritual health. 7 Dec. 2009. <http://www.district6. nbed.nb.ca/districthealth/definitions/ spiritual.aspx $>$.

Ulrich, R.S. 1983. Aesthetic and affective response to natural environment, p. 85125. In I. Altman and J.F. Wohlwill (eds.). Human behavior and environ- ment: Advances in theory and research, Vol. 6. Plenum, New York.

Vader, J. 2006. Spiritual health: The next frontier. Eur. J. Public Health 16:457.

Williams, K. and D. Harvey. 2001. Transcendent experience in forest environments. J. Environ. Psychol. 21:249-260.

Ye, L. 1993. Modern aesthetics system. Bookman Press, Taipei, Taiwan. (In Chinese).
Yu, W.-W., C.-H. Tseng, D.-L. Ling, and Y.-S. Chang. 2006. Aesthetic level and restoration: The restoration theory constructed by Chinese aesthetics. J. Building Planning 13:33-43. (In Chinese).

$\mathrm{Zi}$, A. 2005. Words of a florist. 7 Dec. 2009. <http://blog.yam.com/betsy/ article/845237>. (In Chinese). 